\title{
PARP1 impact on DNA repair of platinum adducts: Preclinical and clinical read-outs
}

\author{
Ken A. Olaussen a,b,c,*, Julien Adam ${ }^{\mathrm{a}, \mathrm{b}, \mathrm{c}}$, Elsa Vanhecke ${ }^{\mathrm{a}, \mathrm{b}, \mathrm{c}}$, Philippe Vielh ${ }^{\mathrm{d}}$, Robert Pirker ${ }^{\mathrm{e}}$, \\ Luc Friboulet $^{\mathrm{a}, \mathrm{b}, \mathrm{c}}$, Helmut Popper ${ }^{\mathrm{f}}$, Angélique Robin ${ }^{\mathrm{a}, \mathrm{b}, \mathrm{c}}$, Fréderic Commo ${ }^{\mathrm{a}, \mathrm{b}, \mathrm{c}}$, \\ Jürgen Thomale $^{g}$, Louis Kayitalire ${ }^{\mathrm{h}}$, Martin Filipits ${ }^{\mathrm{e}}$, Thierry Le Chevalier ${ }^{\mathrm{b}}$, Fabrice André ${ }^{\mathrm{a}, \mathrm{b}, \mathrm{c}}$, \\ Elisabeth Brambilla ${ }^{i}$, Jean-Charles Soria ${ }^{a, b, c}$ \\ a INSERM, U981, Villejuif, France \\ b Institut Gustave Roussy, DHU TORINO, Villejuif, France \\ ${ }^{\mathrm{c}}$ Université Paris Sud, Kremlin-Bicêtre, France \\ d Department of Biopathology, Histocytopathology Unit (LRT) and Biobank, Institut Gustave Roussy, France \\ e Medical University of Vienna, Vienna, Austria \\ ${ }^{\mathrm{f}}$ Medical University of Graz, Graz, Austria \\ ${ }^{g}$ University of Duisburg-Essen Medical School, Essen, Germany \\ h Cephalon Inc. (Tevapharm Inc.), Frazer, PA, USA \\ ${ }^{\mathrm{i}}$ Centre Hospitalier Universitaire Albert Michallon, Grenoble, France
}

\section{A R T I C L E I N F O}

\section{Article history:}

Received 4 October 2012

Received in revised form

21 December 2012

Accepted 19 January 2013

\section{Keywords:}

ERCC1

MSH2

PARP1

Cisplatin

CDDP

Lung cancer

NSCLC biomarkers

Adjuvant chemotherapy

Immunohistochemistry

IALT-bio

\begin{abstract}
A B S T R A C T
Evaluation of DNA repair proteins might provide meaningful information in relation to prognosis and chemotherapy efficacy in Non-Small Cell Lung Cancer (NSCLC) patients. The role of Poly(ADP-Ribose) Polymerase (PARP) in DNA repair of platinum adducts has not been firmly established. We used a DNA repair functional test based on antibody recognition of cisplatin intrastrand platinum adducts on DNA We evaluated the effect of PARP inhibition on DNA repair functionality in a panel of cisplatin cell lines treated by the clinical-grade pharmacological inhibitor CEP8983 (a 4-methoxy-carbazole derivate) and the commercially available inhibitor PJ34 (phenanthridinone). We determined PARP1 protein expression in whole tumor sections from the International Adjuvant Lung cancer Trial (IALT)-bio study and tested a 3-marker PARP1/MSH2/ERCC1 algorithm combining PARP1 tumor status with previously published data. Chemosensitivity of cisplatin in NSCLC cell lines was correlated with the accumulation of cisplatin DNA adducts $(P=0.0004)$. Further, the pharmacological inhibition of PARP induced a 1.7 to 2.3-fold increase in platinum adduct accumulation ( $24 \mathrm{~h}$ ) in A549 cell line suggesting a slow-down of platinum DNA-adduct repair capacity. In parallel, PARP1 inhibition increased the sensitivity to cisplatin treatment. In patient samples, PARP1 expression levels did not influence patient survival or the effect of platinum-based postoperative chemotherapy in the global IALT-bio population (interaction $P=0.79$ ). Among cases with high expression of all three markers (triple positive), untreated patients had prolonged survival with a median DFS of 7.8 years, $(\mathrm{HR}=0.34,95 \% \mathrm{CI}[0.19-0.61]$, adjusted $P=0.0003$ ) compared to triple negative patients (1.4 years). Remarkably, triple positive patients suffered from a detrimental effect (4.9-year reduction of median DFS) by post-operative cisplatin-based chemotherapy ( $\mathrm{HR}=1.79,95 \% \mathrm{CI}$ [1.01-3.17], adjusted $P=0.04$, chemotherapy vs. control). Combinatorial sub-group analysis of the 3 markers further suggested that PARP1 tumor positivity might constitute a molecular context with high theranostic interest of ERCC1 and MSH2 in NSCLC. In conclusion, our data confirm that platinum DNA adduct accumulation is linked to chemosensitivity, which increase by pharmacological PARP inhibitors points to a role of PARP-dependent DNA repair in the process. We further suggest DNA repair biomarkers should be analyzed in a larger context of multiple DNA repair pathway regulation.
\end{abstract}

@ 2013 Elsevier Ireland Ltd. All rights reserved.

\footnotetext{
* Corresponding author at: INSERM U981, Institut Gustave Roussy, 114 rue Edouard Vaillant, 94805 Villejuif, France. Fax: +33 142116094.

E-mail address: ken.olaussen@igr.fr (K.A. Olaussen).
}

\section{Introduction}

The "mutator phenotype" observed in some cancer cells [1] suggests the presence of a functional link between DNA repair dysfunctionality and acquisition of cancer-related mutations. Several reports have demonstrated that DNA repair acts as a "barrier" 
against oncogenesis [2]. Therefore, DNA repair dysfunctionality is expected to influence upon the natural history of cancer.

Platinum-based post-operative chemotherapy has become a standard in patients with resected Non-Small Cell Lung Cancer (NSCLC). Cisplatin is a DNA damaging agent that induces mainly intrastrand platinum (Pt) adducts between GG, AG or GXG. The altered DNA results in transcription and replication failures leading to cell death. We and others have previously shown that clinical efficacy of cisplatin depends on the expression levels of DNA repair proteins such as Excision Repair Cross Complementing 1 (ERCC1) and Mut S Homolog 2 (MSH2), involved in Nucleotide excision repair (NER), Interstrand Cross-link repair (ICL-R) and mismatch repair (MMR) pathways [3,4].

Unrepaired platinum adducts or cross-links might lead to secondary lesions such as single- and double-strand breaks. Poly(ADP-Ribose) Polymerase 1 (PARP1) is a protein that recognizes and signals single-stranded DNA lesions allowing the activation of the Base excision repair (BER) pathway [5]. The repression of PARP1 activity is sufficient to induce cell death in cancer cells bearing BRCA1 or BRCA2 homozygous mutations, which are essential in the Homologous Recombination Repair (HRR) pathway [6,7]. Emerging data suggest that PARP inhibition induce a chemosensitizing effect in platinum-based regimens in specific contexts of DNA repair dysfunctionality $[8,9]$. Further, PARP proteins from cell extracts can bind platinum modified DNA in order to facilitate the dissociation of nuclear proteins $[10,11]$. However, little is known about the efficacy of platinum adduct DNA repair after PARP inhibition or the consequence of loss of PARP protein expression in tumors from NSCLC patients.

Here, we studied cisplatin sensitivity and functionality of DNA repair following cisplatin treatment in vitro with or without pharmacological inhibition of PARP1. We also investigated the expression levels in situ of PARP1 using whole tumor sections of resected NSCLC tumors from the International Adjuvant Lung cancer Trial (IALT)-bio study. PARP1 expression status was analyzed in combination with ERCC1 and MSH2 expression statuses, since all three proteins represent distinct DNA repair pathways that could impact cisplatin efficacy.

\section{Materials and methods}

\subsection{Cell lines, cultures and drug preparations}

The 16 NSCLC cell lines HCC827, H1650, H1975, HOP62, H2342, H1563, BEN, H1299, H226, H358, A549, H1666, H460, H1651, H1793, and H2228 were grown in RPMI 1640 or DMEM medium (Gibco-Invitrogen) supplemented with $10 \%$ fetal calf serum (FCS). The specific PARP-inhibitor CEP8983 was obtained from Cephalon (West Chester, PA, USA) and diluted in dimethyl sulfoxide (DMSO) at $50 \mathrm{mM}$ and conserved in small aliquots at $-20^{\circ} \mathrm{C}$. PJ34 (Sigma-Aldrich) was diluted in water at $50 \mathrm{mM}$ and conserved in aliquots at $-20^{\circ} \mathrm{C}$. Cisplatin was obtained from Merck laboratories and used in DNA Repair experiments at $25 \mu \mathrm{M}$.

\subsection{Patients and tumor material}

All patients were from the IALT-Bio study, whose repository has been described previously $[13,14]$. It encompasses paraffin blocks from completely resected patients included in the IALT clinical trial [15] that compared outcomes of patients assigned to observation (control group) or post-operative cisplatin-based chemotherapy. Paraffin blocks from resected tumors were sectioned and applied onto histological Polysine ${ }^{\circledR}$ glass slides (Thermo Fisher Scientific Inc.).

\subsection{Cell proliferation assay}

Cell viability was estimated using the Cell Proliferation Reagent WST-1 (Roche Applied Science). Cells were seeded in 96-well plates and treated with various concentrations of cisplatin. IC50 of cisplatin was determined after $48 \mathrm{~h}$ of treatment. To evaluate the effect on cisplatin IC50 values by PARP inhibition, cells were treated with CEP8983 at $10 \mu \mathrm{M}$ or PJ34 at $30 \mu \mathrm{M}$ and various concentrations of cisplatin for $72 \mathrm{~h}$.

\subsection{Dot blots}

A functional test of DNA repair capacity of platinum adducts was used as described previously [12]. The technique is based on the kinetic quantification of cisplatin intrastrand DNA adducts (Pt-[GG]) recognized by the rat monoclonal antibody R-C18. Cells were seeded in 6 -well plates, treated with cisplatin for $2 \mathrm{H}$ and left untreated for different incubation times in presence or not of CEP8983 $10 \mu \mathrm{M}$ or PJ34 $30 \mu \mathrm{M}$. DNA was extracted using a Qiagen kit and RNase treated. $2 \mu \mathrm{g}$ single stranded DNA was spotted on a nylon hybond membrane in a vacuum generating apparatus (Bio-Rad). R-C18 staining was revealed by horseradish-peroxidaseconjugated anti-rat monoclonal antibody followed by ECL detection kit (Amersham Pharmacia). Dot intensities were subjected to image analysis (ImageJ) and digitally quantified at the following 6 time points: $h_{0}$ (before treatment), $h_{1}$ (after $1 \mathrm{~h}$ of treatment), $h_{2}$ (end of treatment), $h_{2+3}$ ( $3 \mathrm{~h}$ after end of treatment, i.e. $5 \mathrm{~h}$ after treatment start), $h_{2+6}$ ( $6 \mathrm{~h}$ after end of treatment) and $h_{2+24}(24 \mathrm{~h}$ after end of treatment). The accumulation of DNA adducts over time (air under the curve, AUC) was roughly estimated by adding the signal intensities observed at all of the 6 time points.

\subsection{Western blots}

PAR Western blotting was used as positive control of PARP1 inhibition. A549 cells were treated overnight with PARP inhibitors and cisplatin then whole-cell protein extracts $(40 \mu \mathrm{g})$ were loaded on an SDS page gel. Transferred proteins were then revealed using an anti-PAR antibody (MAB 3192 Millipore) or GAPDH antibody (Sigma) as loading control.

\subsection{Immunostaining}

PARP1 immunostaining was performed on 678 whole-tumor sections of the IALT-bio cohort using a standard procedure. Tumor sections were deparaffinized and heated at $98^{\circ} \mathrm{C}$ for $30 \mathrm{~min}$ in $10 \mathrm{mM}$ citrate buffer (pH6.0). Slides were incubated with the anti-PARP1 (1:4000 dilution) monoclonal antibody (clone A6.4.12, from AbD Serotec) at room temperature for $60 \mathrm{~min}$. Slides were washed and incubated for $30 \mathrm{~min}$ at room temperature with the secondary antibody (Vectastain ${ }^{\circledR}$ Universal Elite ABC Kit, Vector Laboratories Inc.). Revelation was performed by the streptavidinbiotin-peroxidase complex method and DAB+ (Dako). PARP1 immunostaining was independently evaluated by two pathologists (JA and PV) blinded to clinical data. The sections were examined for PARP1-reactive lung stroma and tumor cells. The staining intensity was graded on a $0-3$ scale (absence of reactivity as 0 , low as 1 , medium as 2 , and strong as 3 ). The percentage of reactive tumor cells (nucleus only) was noted on a $0-100 \%$ scale. For each patient, a final PARP1 score (ranging from 0 to 300 ) was defined as the product between intensity and percentage of stained tumor cells. The cutoff value for patient stratification on PARP1 was arbitrarily chosen as the median score among all patients. 


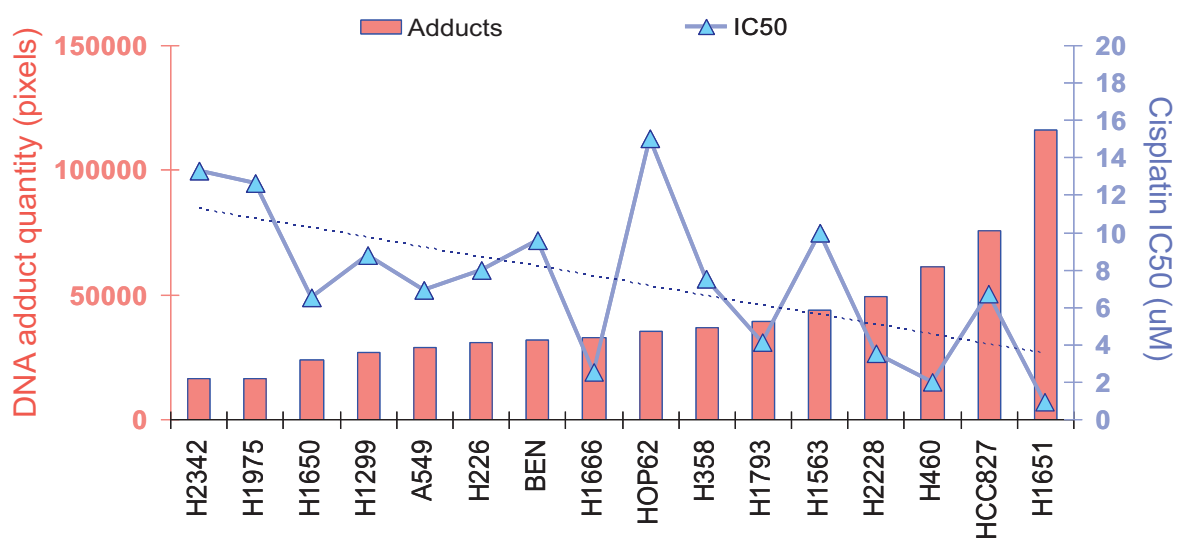

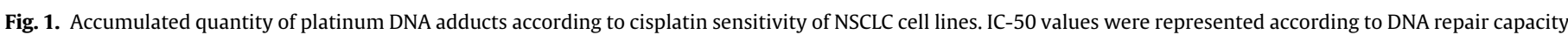
of platinum adducts in cell lines.

\subsection{DNA repair multimarker score}

In order to test the effect of increasing/decreasing number of DNA repair pathway dysfunctionality on patient survival, we used PARP1 status in combination with our data published on MSH2 (2010) and ERCC1 (2006). Hence, four groups were defined as follows: Group 0 (all markers stained negative), group 1 (1 positive marker, 2 negative markers), group 2 ( 2 positive markers, 1 negative marker), and group 3 (positive staining for all 3 markers).

\subsection{Statistical analysis}

Long-term IALT survival data were used with a median followup of 7.5 years. The prognostic analyses of marker groups on survival were studied using Cox analysis. Other tests were also performed: heterogeneity test, and trend test. The predictive value of the biomarker was studied by testing the interaction between the biomarker status and the allocated treatment (chemotherapy or no chemotherapy) in the Cox model. All reported $P$ values were two-sided. Survival rates were estimated using the Kaplan-Meier method.

\section{Results}

\subsection{Effect of platinum adduct accumulation and clearance (DNA} repair capacity) on chemosensitivity of NSCLC cell lines

We first established cisplatin IC50 values in 16 NSCLC cell lines (Fig. 1). The same cell lines were subjected to $2 \mathrm{~h}$ of cisplatin treatment for quantification of DNA adducts using the R-C18 antibody that specifically recognizes Platinum-[GG] intrastrand adducts. These results were superposed to IC50 values in Fig. 1 where cell lines were ranged in the order of increasing signal accumulated (AUC) after $24 \mathrm{~h}$ post-treatment. The cells accumulated DNA adducts in the following order (from low to high quantity of DNA adduct accumulation): H2342, H1975, H1650, H1299, A549, H226, BEN, H1666, HOP62, H358, H1793, H1563, H2228, H460 HCC827, and H1651. There was a global trend between accumulation levels of DNA adducts and cisplatin sensitivity in NSCLC cells. Cisplatin resistant cell lines such as H2342 or H1975 displayed low intrastrand Pt[GG] adduct accumulation compared to highly sensitive cell lines such as $\mathrm{H} 460$ or H1651, both with high levels of adduct accumulation $\left(R^{2}=0.581, P=0.0004\right)$.

\subsection{Effect of PARP inhibition on DNA repair capacity of platinum adducts and on chemosensitivity in vitro}

Compared to control, the pharmacological inhibition of PARP induced a 2.3-fold increase in the overall accumulation of DNA platinum adducts using PJ34 (diluted in water) and a 1.7-fold increase using CEP8983 (diluted in DMSO) (Fig. 2A). As expected, the inhibition of PARP was accompanied by a blockade of PARactivity (both baseline and cisplatin-induced activity) (Fig. 2B). The PARP inhibition-induced reduction of DNA repair capacity was further accompanied by a significant increase in cisplatin sensitivity of A549 cells (Fig. 2C). In contrast, DMSO treatment alone increased DNA adduct accumulation compared to $\mathrm{H}_{2} \mathrm{O}$, but did not decrease cell viability. Overall, these findings suggest that cisplatin chemosensitization by PARP inhibitors is related to a reduction of DNA repair capacity of platinum adducts.

\subsection{Expression of PARP1 in lung cancer patients and effect on survival (prognostic and predictive analysis)}

In the overall study-population, PARP1 status (positive or negative tumor expression) had no effect on overall survival or disease-free survival (HR positive vs. negative $=0.9195 \% \mathrm{CI}$ [0.67-1.23] $P=0.53$ for DFS). With regard to post-operative chemotherapy there was no predictive effect of PARP1 level status on patient survival (on DFS the HR (chemotherapy vs. control $)=0.85,95 \% \mathrm{CI}[0.64-1.14], P=0.28$ in PARP1 negative patients compared to $\mathrm{HR}=1.00,95 \% \mathrm{CI}[0.74-1.35], P=1.00$ in PARP1 positive patients, (interaction test, $P=0.79)$ ).

\subsection{Combined expression of ERCC1, MSH2, and PARP1 in lung cancer patients and effect on survival (prognostic analysis)}

The expression levels of the 3 DNA repair proteins were mutually dependent: the proportion of $\mathrm{MSH} 2$ positive patients was higher in ERCC1 positive than among ERCC1 negative patients (49\% vs. $28 \%$, Chi-square $P<0.0001$ ), the proportion of PARP1 positive patients was higher among MSH2 positive than among MSH2 negative patients ( $57 \%$ vs. $44 \%$, Chi-square $P=0.002$ ), and the proportion of PARP1 positive patients was higher in ERCC1 positive than among ERCC1 negative patients ( $56 \%$ vs. $44 \%$, Chi-square $P=0.005$ ). In the global study population, $23 \%$ of patients $(131 / 570)$ were positive for none of the 3 markers, compared to $14 \%(80 / 570)$ whose tumors were classified "triple positive". In the control group (no postoperative chemotherapy), $14 \%$ of patients (39/279) had a "triple positive" signature. The median DFS of triple positive patients was 
A
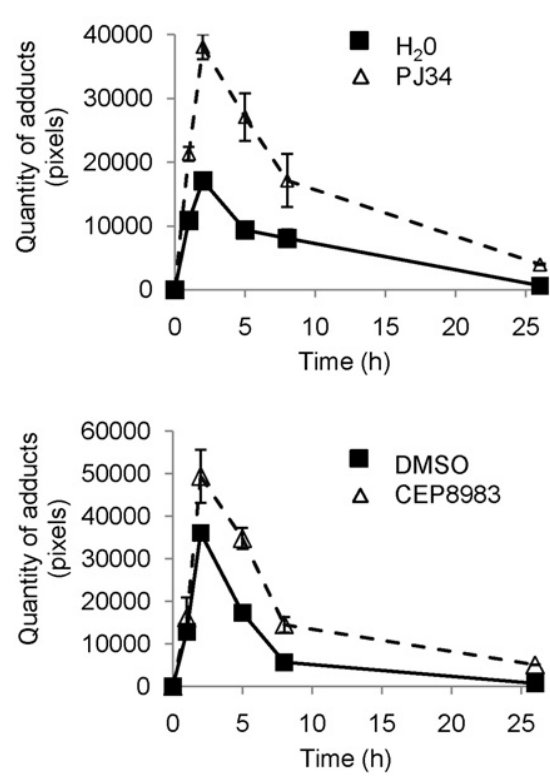

B

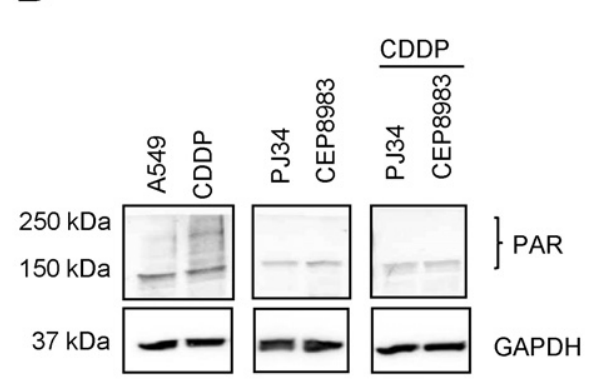

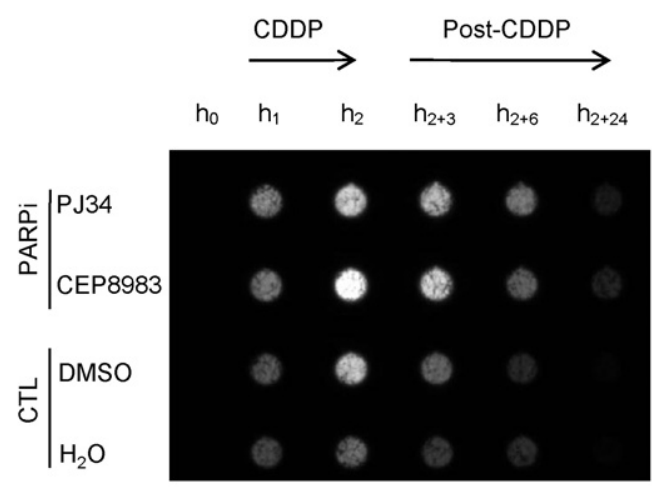
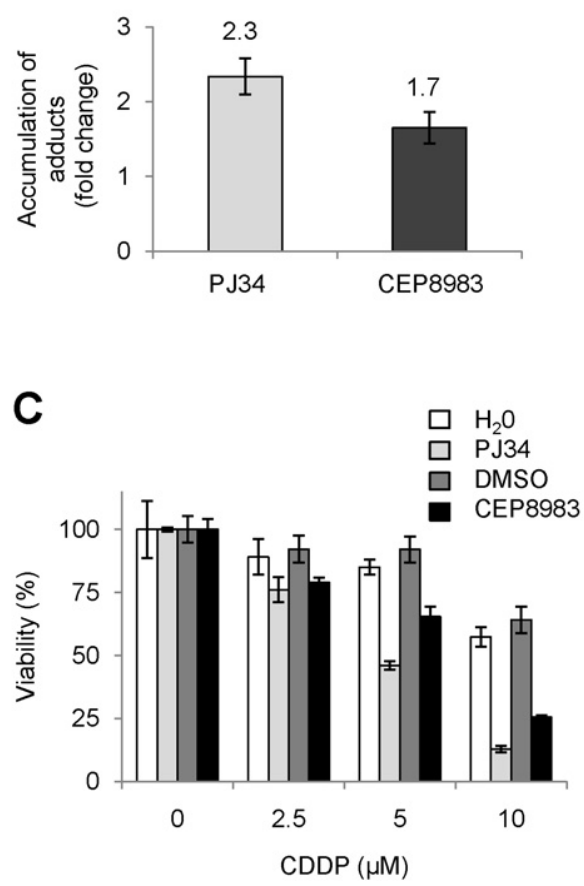

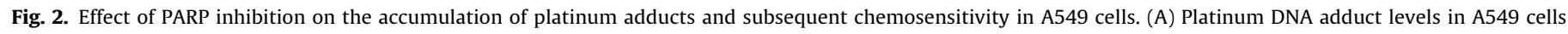

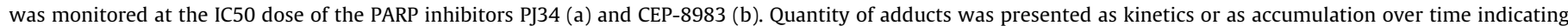

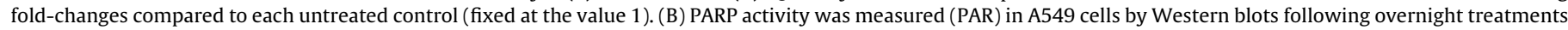
of PJ34 (a) or CEP-8983 (b) and cisplatin. (C) Cell viability was measured after $72 \mathrm{~h}$ of treatment at IC50 of PJ34 (a) and CEP-8983 (b) combined or not with cisplatin.

7.8 years $(\mathrm{HR}=0.34,95 \mathrm{CI}[0.19-0.61], P=0.0003)$ compared to 1.4 years in triple negative patients (i.e. a difference of 6.4 years, $P$ for trend $=0.0004$ ) (Table 1 and Fig. 3A). Similar data were found for overall survival (OS) with a significant trend of shortened overall survival with increasing number of negative biomarkers (data not shown). We further subdivided each of the biomarker groups into 8 separate subgroups based on every possible combination of the 3 markers (Table 1). The PARP1+/MSH2-/ERCC1- group had a hazard ratio close to the reference group (triple negative) with $\mathrm{HR}=0.96$, $95 \% \mathrm{CI}[0.59-1.56], P=0.86$, which is in contrast to the favorable hazard ratio observed in PARP1+/MSH2+/ERCC1+ patients $(\mathrm{HR}=0.34$, 95CI [0.19-0.61], $P=0.0003$ ).

\subsection{Combined expression of DNA repair markers on the benefit of adjuvant chemotherapy (predictive analysis)}

When comparing chemotherapy group vs. control group, the triple positive patients demonstrated an adjusted hazard ratio for death associated with post-operative chemotherapy of $1.79(95 \% \mathrm{CI}$ [1.01-3.17], adjusted $P=0.04$, DFS). Indeed, triple positive patients who received chemotherapy had significantly shorter median DFS
(2.9 years) compared to triple positive patients in the control group (7.8 years, adjusted $P=0.04$ ) (Table 2 and Fig. $3 \mathrm{~A}$ and $\mathrm{B}$ ) indicating a deleterious effect from post-operative chemotherapy in triple positive patients. Similar data were found for OS $(\mathrm{HR}=1.81$ 95\%[1.02-3.21], adjusted $P=0.04$ in triple positive patients, not shown). The subdivision into 8 subgroups based on every possible combination of the 3 markers (Table 2) confirmed the insignificant role per se by PARP1 compared to ERCC1 and MSH2. However, the combined ERCC1 and MSH2 status (both positive vs. both negative) showed a larger spread between hazard ratios and lesser overlapping confidence intervals when considering only PARPpositive patients. The PARP1+/MSH2-/ERCC1 - group had a HR = 0.62 (95\%CI [0.36-1.04]) in favor of chemotherapy vs. no chemotherapy, which is in strong contrast to PARP1+/MSH2+/ERCC1+ patients who had a significant risk of death from post-operative chemotherapy ( $\mathrm{HR}=1.79 ; 95 \% \mathrm{CI}[1.01-3.17])$.

\section{Discussion}

Here, we observed in A549 cells a sensitizing effect to cisplatin by PARP inhibition that was accompanied by an increase of 
Table 1

Prognostic analysis: DFS according to biomarker subgroups in patients who did not receive post-operative chemotherapy (control population).

\begin{tabular}{|c|c|c|}
\hline DFS & $\begin{array}{l}\text { Control group } \\
N=279 \text { number of } \\
\text { events/number of } \\
\text { patients }\end{array}$ & $\begin{array}{l}\text { HR for events } \\
{[95 \% \mathrm{CI}] P \text {-value }}\end{array}$ \\
\hline Group 0: $\mathrm{P}-\mathrm{M}-\mathrm{E}-$ & $49 / 64$ & $\begin{array}{l}1 \\
\text { (reference) }\end{array}$ \\
\hline Group $1_{1}: P+M-E-$ & $30 / 44$ & $\begin{array}{l}0.96 \\
{[0.59 ; 1.56]} \\
0.86\end{array}$ \\
\hline Group $1_{2}: P-M+E-$ & $12 / 17$ & $\begin{array}{l}0.58 \\
{[0.29 ; 1.13]} \\
0.11\end{array}$ \\
\hline Group $1_{3}: P-M-E+$ & $22 / 41$ & $\begin{array}{l}0.50 \\
{[0.29 ; 0.87]} \\
0.01\end{array}$ \\
\hline Group $2_{1}: \mathrm{P}-\mathrm{M}+\mathrm{E}+$ & $20 / 26$ & $\begin{array}{l}0.58 \\
{[0.33 ; 1.02]} \\
0.06\end{array}$ \\
\hline Group $2_{2}: \mathrm{P}+\mathrm{M}-\mathrm{E}+$ & $19 / 28$ & $\begin{array}{l}0.60 \\
{[0.34 ; 1.07]} \\
0.08\end{array}$ \\
\hline Group $2_{3}: P+M+E-$ & $13 / 20$ & $\begin{array}{l}0.48 \\
{[0.25 ; 0.91]} \\
0.02\end{array}$ \\
\hline Group 3: $\mathrm{P}+\mathrm{M}+\mathrm{E}+$ & $20 / 39$ & $\begin{array}{l}0.34 \\
{[0.19 ; 0.61]} \\
0.0003\end{array}$ \\
\hline
\end{tabular}

$\mathrm{P}=\mathrm{PARP} 1, \mathrm{M}=\mathrm{MSH} 2, \mathrm{E}=\mathrm{ERCC}$; $\mathrm{DFS}=$ disease-free survival; $\mathrm{Cl}$ : confidence interval; heterogeneity test: $P=0.01$.

platinum intrastrand adduct formation. When PARP1 expression status was included in a 3-marker algorithm together with ERCC1 and MSH2 status, the triple positive-group was associated with a remarkable favorable outcome of resected NSCLC patients, but also a detrimental effect from post-operative chemotherapy.

The preclinical results give some support to the hypothesis that PARP is implicated in platinum DNA adduct repair. Indeed, PARP inhibition clearly increased accumulation of intrastrand $\mathrm{Pt}[\mathrm{GG}]$ adducts above levels of control cells. However, DNA adduct accumulation is normally a result of several combined mechanisms such as influx/transport rates, detoxification and intrinsic DNA repair capacity. Therefore, all these factors certainly play a role both during the treatment period and post-treatment period (clearance). Interestingly, the reduction of DNA repair capacity by PARP inhibition seemed to be necessary for chemosensitizing the cells to cisplatin since DMSO alone (that increases adduct accumulation through a mechanism of increased cell membrane permeability) had no effect on cell viability after cisplatin treatment.

These pre-clinical data led us to test the hypothesis whether tumors with loss of PARP expression would have higher benefit from platinum-based chemotherapy, but there was no such predictive effect of PARP1 alone. However, we found interesting data when combining PARP1 status with ERCC1 and MSH2 status. Triple positivity of ERCC1, MSH2 and PARP1 expression in tumors indicated excellent survival rates in patients randomized to observation after surgery. Triple positivity of ERCC1, MSH2 and PARP1 in tumors might indicate a high DNA repair capacity that acts as a molecular "barrier" against the acquisition of malignant properties in cells such as post-operative residual tumor cells. We recently reported that ERCC1 negative NSCLC tumors display high rate of overall genomic gains/loss [16]. Further investigations are needed to confirm that triple negative patients have high genomic aberration rates.

In contrast, there was a significant deleterious effect on patient survival rates from post-operative chemotherapy in triple positive patients compared to untreated patients. The reason why post-operative cisplatin based chemotherapy is detrimental in triple-positive patients remains elusive. The presence of a selective pressure by cisplatin favoring survival of tumor cells with positive status of all 3 repair markers is one possible explanation. The infidelity of many DNA repair processes leading to the acquisition of new mutations and to the formation of more aggressive/resistant tumor clones, constitute another hypothesis. Other authors have suggested that some tumors increase the expression of DNA repair genes as an attempt to contain lethal accumulation of DNA damage, which in turn influences radiosensitivity and more advanced disease presentation [17].

Table 2

predictive analysis: DFS according to allocated treatment and subgroup analysis.

\begin{tabular}{|c|c|c|c|}
\hline DFS & $\begin{array}{l}\text { CT group } N=291 \text { number of } \\
\text { events/number of patients }\end{array}$ & $\begin{array}{l}\text { Control group } N=279 \\
\text { number of events/number } \\
\text { of patients }\end{array}$ & $\begin{array}{l}\text { HR for events CT vs. no } \\
\text { CT [ } 95 \% \mathrm{CI}] P \text {-value }\end{array}$ \\
\hline Group 0: P- M- E- & $43 / 67$ & $49 / 64$ & $\begin{array}{l}0.69 \\
{[0.45 ; 1.06]} \\
0.09\end{array}$ \\
\hline Group $1_{1}: P+M-E-$ & $29 / 46$ & $30 / 44$ & $\begin{array}{l}0.62 \\
{[0.36 ; 1.04]} \\
0.07\end{array}$ \\
\hline Group $1_{2}: P-M+E-$ & $14 / 24$ & $12 / 17$ & $\begin{array}{l}1.01 \\
{[0.46 ; 2.22]} \\
0.97\end{array}$ \\
\hline Group $1_{3}: P-M-E+$ & $12 / 27$ & $22 / 41$ & $\begin{array}{l}0.64 \\
{[0.32 ; 1.29]} \\
0.21\end{array}$ \\
\hline Group $2{ }_{1}: P-M+E+$ & $19 / 24$ & $20 / 26$ & $\begin{array}{l}1.23 \\
{[0.64 ; 2.34]} \\
0.54\end{array}$ \\
\hline Group $2_{2}: \mathrm{P}+\mathrm{M}-\mathrm{E}+$ & $26 / 39$ & $19 / 28$ & $\begin{array}{l}0.96 \\
{[0.53 ; 1.76]} \\
0.90\end{array}$ \\
\hline Group $2_{3}: P+M+E-$ & $10 / 23$ & $13 / 20$ & $\begin{array}{l}0.76 \\
{[0.33 ; 1.75]} \\
0.52\end{array}$ \\
\hline Group 3: $\mathrm{P}+\mathrm{M}+\mathrm{E}+$ & $31 / 41$ & $20 / 39$ & $\begin{array}{l}1.79 \\
{[1.01 ; 3.17]} \\
0.04\end{array}$ \\
\hline
\end{tabular}

$\mathrm{P}=\mathrm{PARP} 1, \mathrm{M}=\mathrm{MSH} 2 \mathrm{E}=\mathrm{ERCC} 1$; DFS = disease-free survival; $\mathrm{CI}$ : confidence interval; $\mathrm{CT}$ = post-operative chemotherapy; heterogeneity test: $P=0.13$. 

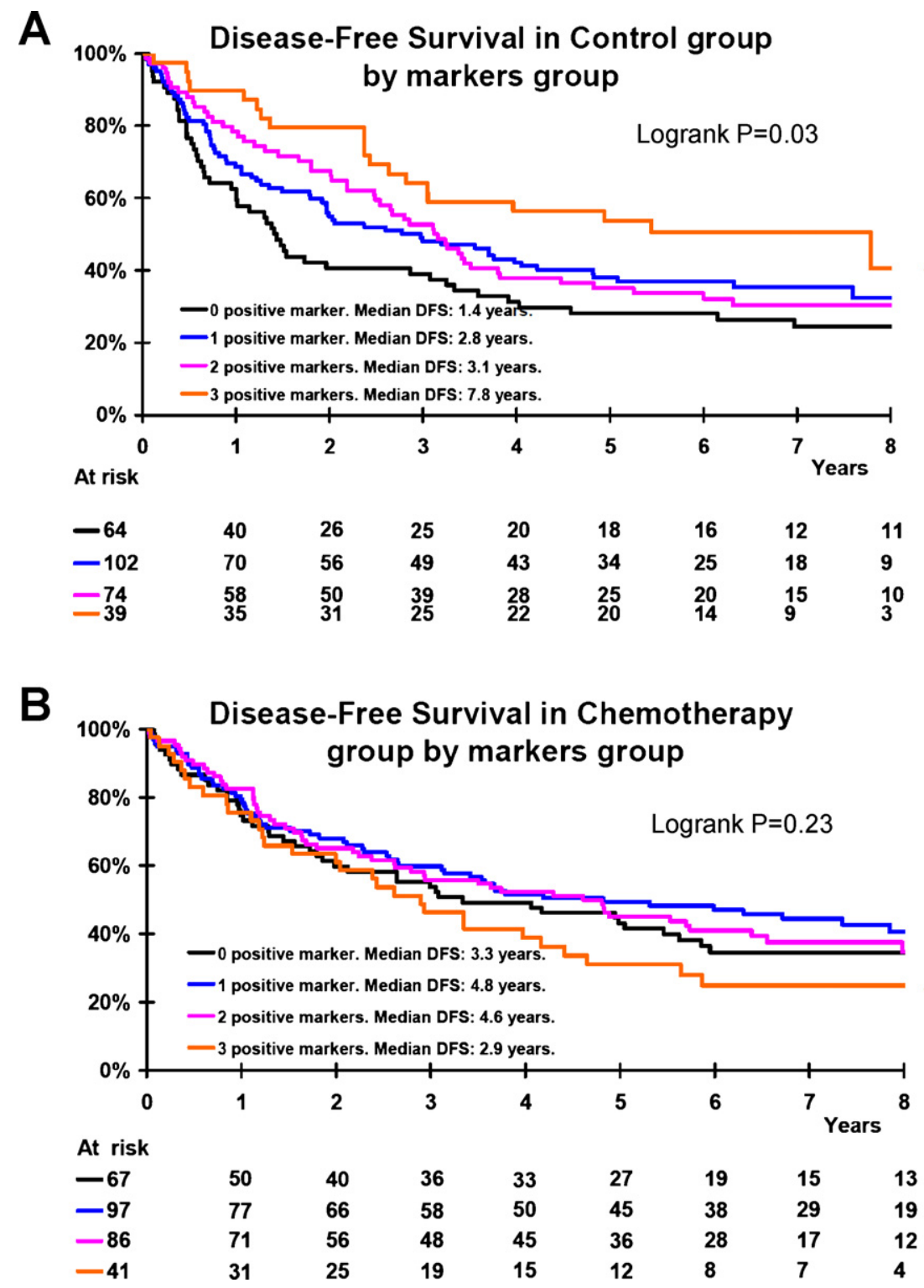

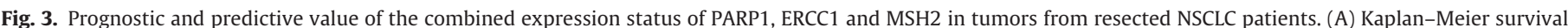

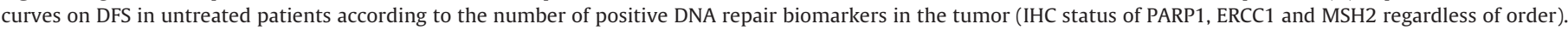

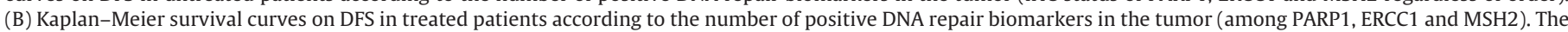

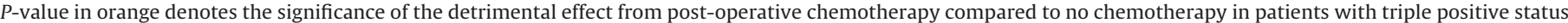
of the markers.

A major challenge is to understand how triple positivity and triple negativity can constitute the 2 groups with the strongest significant theranostic interest in NSCLC, while PARP1 alone has no effect on survival. Is it simply fortunate (statistical sampling effect) or is it a biologically relevant finding? The question remains open, but the data suggest some DNA repair biomarkers should be considered in particular contexts implicating several pathways simultaneously. It is noteworthy that ERCC1 and MSH2 discriminate the risk for death and efficacy of chemotherapy mostly in PARP-positive patients. PARP1 positivity and negativity might somehow reflect two different molecular contexts, where the statuses of other DNA repair markers are impacting prognosis and efficacy of cisplatin-based chemotherapy in distinct manners.

The present data should be placed into a perspective with our previous reports on DNA repair markers using different sampling procedures (small cores on a Tissue Micro Array (TMA), and different analysis systems (digital-based automated evaluation) [18]. In that study, PARP1 was not a prognostic or predictive biomarker in the global IALT-population, but showed a statistically borderline theranostic interest in squamous cell carcinomas (SCCs). A further sub-analysis of the present three-marker algorithm on different histological classes would certainly lead to highly interesting models, though with too poor statistical power to be correctly analyzed.

In conclusion, PARP inhibition increases cisplatin-induced Pt[GG] adduct accumulation in A549 cells, with consequent increase in cisplatin chemosensitivity. Therefore, increased platinum-adduct accumulation combined with functional inhibition of the DNA repair protein PARP might determine cisplatin efficacy in NSCLC. Despite these findings, PARP1 has no predictive value alone for post-operative cisplatin-based chemotherapy in NSCLC patients. However, when interrogated in the setting of multiple DNA repair markers the inclusion of PARP1 expression allowed the identification of particular subgroups with high theranostic interest. Upcoming studies on DNA repair dysfunctionality will certainly identify small NSCLC patient subgroups with clearly distinct clinical fates. 


\section{Conflict of interest statement}

Louis Kayitalire is an employee of Cephalon Inc. All other authors declare no conflict of interest.

\section{Acknowledgments}

INCa PNES Poumon. An unrestricted research grant was obtained from Eli Lilly. Inc.

\section{References}

[1] Loeb LA. Human cancers express mutator phenotypes: origin, consequences and targeting. Nat Rev Cancer 2011;11:450-7.

[2] Bartkova J, Horejsi Z, Koed K, Krämer A, Tort F, Zieger K, et al. DNA damage response as a candidate anti-cancer barrier in early human tumorigenesis. Nature 2005;434:864-70.

[3] Kamal NS, Soria JC, Mendiboure J, Planchard D, Olaussen KA, Rousseau V, et al. MutS homologue 2 and the long-term benefit of adjuvant chemotherapy in lung cancer. Clin Cancer Res 2010;16:1206-15.

[4] Olaussen KA, Dunant A, Fouret P, Brambilla E, André F, Haddad V, et al. DNA repair by ERCC1 in non-small-cell lung cancer and cisplatin-based adjuvant chemotherapy. N Engl J Med 2006;355:983-91.

[5] Parsons JL, Dianova II, Allinson SL, Dianov GL. Poly(ADP-ribose) polymerase1 protects excessive DNA strand breaks from deterioration during repair in human cell extracts. FEBS J 2005;272:2012-21.

[6] Bryant HE, Schultz N, Thomas HD, Parker KM, Flower D, Lopez E, et al. Specific killing of BRCA2-deficient tumours with inhibitors of poly(ADP-ribose) polymerase. Nature 2005;434:913-7.

[7] Farmer H, McCabe N, Lord CJ, Tutt AN, Johnson DA, Richardson TB, et al. Targeting the DNA repair defect in BRCA mutant cells as a therapeutic strategy. Nature 2005;434:917-21.

[8] Clark CC, Weitzel JN, O'Connor TR. Enhancement of synthetic lethality via combinations of ABT-888 (a PARP inhibitor) and carboplatin in vitro and in vivo using BRCA1 and BRCA2 isogenic models. Mol Cancer Ther 2012;11: 1948-58.

[9] Fong PC, Yap TA, Boss DS, Carden CP, Mergui-Roelvink M, Gourley C, et al. Poly(ADP)-ribose polymerase inhibition: frequent durable responses in BRCA carrier ovarian cancer correlating with platinum-free interval. J Clin Oncol 2010;28:2512-9.

[10] Guggenheim ER, Ondrus AE, Movassaghi M, Lippard SJ. Poly(ADP-ribose) polymerase- 1 activity facilitates the dissociation of nuclear proteins from platinum-modified DNA. Bioorg Med Chem 2008;16:10121-8.

[11] Guggenheim ER, Xu D, Zhang CX, Chang PV, Lippard SJ. Photoaffinity isolation and identification of proteins in cancer cell extracts that bind to platinummodified DNA. Chembiochem 2009;10:141-57.

[12] Liedert B, Pluim D, Schellens J, Thomale J. Adduct-specific monoclonal antibodies for the measurement of cisplatin-induced DNA lesions in individual cel nuclei. Nucleic Acids Res 2006;34:e47.

[13] Dunant A, Pignon JP, Le Chevalier T. Adjuvant chemotherapy for non-small cell lung cancer: contribution of the International Adjuvant Lung Trial. Clin Cance Res 2005;11:5017s-21s.

[14] Filipits M, Pirker R, Dunant A, Lantuejoul S, Schmid K, Huynh A, et al. Cell cycle regulators and outcome of adjuvant cisplatin-based chemotherapy in completely resected non-small-cell lung cancer: the International Adjuvant Lung Cancer Trial Biologic Program. J Clin Oncol 2007;25:2735-40.

[15] Arriagada R, Bergman B, Dunant A, Le Chevalier T, Pignon JP, Vansteenkiste J. Cisplatin-based adjuvant chemotherapy in patients with completely resected non-small-cell lung cancer. N Engl J Med 2004;350:351-60.

[16] Friboulet L, Barrios-Gonzales D, Commo F, Olaussen KA, Vagner S, Adam J, et al Molecular characteristics of ERCC1-negative versus ERCC1-positive tumors in resected NSCLC. Clin Cancer Res 2011;17:5562-72.

[17] Lima LM, de Souza LR, da Silva TF, Pereira CS, Guimarães AL, de Paula AM, et al. DNA repair gene excision repair cross complementing-group 1 (ERCC1) in head and neck squamous cell carcinoma: analysis of methylation and polymorphism (G19007A), protein expression and association with epidemiological and clinicopathological factors. Histopathology 2012;60:489-96.

[18] Pierceall WE, Olaussen KA, Rousseau V, Brambilla E, Sprott KM, Andre F et al. Cisplatin benefit is predicted by immunohistochemical analysis of DNA repair proteins in squamous cell carcinoma but not adenocarcinoma: theranostic modeling by NSCLC constituent histological subclasses. Ann Onco 2012;23:2245-52 